\title{
Early Retinal Findings Following Cooling in Neonatal Encephalopathy
}

\author{
Mustafa Ali Akin ${ }^{1}$ Ozlem Sahin ${ }^{1} \quad$ Murat Cansever $^{2}$ \\ ${ }^{1}$ Division of Neonatology, Department of Pediatrics, University of \\ Medical Sciences Kayseri Training and Research Hospital, Kocasinan, \\ Kayseri, Turkey \\ ${ }^{2}$ Department of Pediatrics, University of Medical Sciences Kayseri \\ Training and Research Hospital, Kocasinan, Kayseri, Turkey \\ ${ }^{3}$ Department of Ophthalmology, University of Medical Sciences \\ Kayseri Training and Research Hospital, Kocasinan, Kayseri, Turkey \\ ${ }^{4}$ Department of Neonatology, UCL EGA Institute for Women's Health \\ (IfWH), University College London, London, United Kingdom
}

Ender Sirakaya ${ }^{3}$ Nicola Jayne Robertson ${ }^{4}$

Neuropediatrics

\author{
Address for correspondence Mustafa Ali Akin, MD, Division of \\ Neonatology, Department of Pediatrics, University of Medical \\ Sciences Kayseri Training and Research Hospital, 38090 Kocasinan, \\ Kayseri, Turkey (e-mail: mustafaaliakin@hotmail.com).
}

\begin{abstract}
Keywords

- hypothermia

- perinatal hypoxiaischemia

- newborn

- retinal hemorrhage

Background and Aim Perinatal HI (hypoxia-ischemia)-related visual defects including blindness are known to be associated with ischemic lesions in intracerebral visual pathways and ischemic retinal damage (IRD). Intraocular hemorrhages (IOH) such as retinal hemorrhage $(\mathrm{RH})$, which may result from perinatal $\mathrm{HI}$, can cause IRD by various mechanisms. We aimed to evaluate the early retinal findings in neonates with moderate-to-severe neonatal encephalopathy (NE) who underwent $\mathrm{TH}$ and its relationship between coagulation status, amplitude-integrated electroencephalography (aEEG) patterns, and magnetic resonance imaging-magnetic resonance spectroscopy (MRI-MRS) findings.

Method and Patients A total of 31 newborn infants who underwent moderate-tosevere $\mathrm{NE}$ and $\mathrm{TH}$ included in the study. Coagulation parameters were taken immediately before starting $\mathrm{TH}$, and daily during $\mathrm{TH}$ period. aEEG records were obtained during $\mathrm{TH}$ and rewarming period.

Binocular indirect ophthalmoscopic examination (BIOE) and MRI-MRS scanning were performed when TH protocol completed.

Results Total $13(41.9 \%)$ patients had abnormal BIOE findings. Ten of them were (77\%) $\mathrm{IOH}$, other findings are as follows: $\mathrm{RH}(n=7)$, optic disc hemorrhage $(n=2)$, and vitreous hemorrhage $(n=1)$. Initial coagulation status was not related to $\mathrm{IOH}$. Worsened aEEG and MRI-MRS results were not related to BIOE findings.

Conclusion Frequency of $\mathrm{IOH}$ is high in newborns with NE who underwent TH being independent from severity of MRS-MRI findings, aEEG pattern, and disturbed coagulation status.
\end{abstract}

\section{Introduction}

Neonatal encephalopathy (NE) is a descriptive term for clinical conditions characterized by neurological dysfunction including difficulty with initiating and maintaining respiration, depression of tone and reflexes, subnormal level of consciousness, and seizures. ${ }^{1} \mathrm{NE}$ has a complex and multifactorial etiology, which includes perinatal hypoxiaischemia (HI). Perinatal HI can damage all organ systems particularly the central nervous system (CNS). Long-term sequelae of NE include attention-deficit hyperactivity disorder epilepsy, developmental delay, spasticity and hearing received

February 21, 2018

accepted after revision

July 22, 2018 (c) Georg Thieme Verlag KG

Stuttgart · New York
DOI https://doi.org/ 10.1055/s-0038-1669425. ISSN $0174-304 X$. 
alterations or visual problems including blindness. ${ }^{2}$ The retina, as an extension of the brain, is also sensitive to hypoxia. $^{3,4}$

It is well known that perinatal $\mathrm{HI}$ and the resulting $\mathrm{NE}$ impact on vision in term newborns. Visual defects related to hypoxic brain damage are currently the most common and potentially preventable cause of visual impairment in children in developed countries. ${ }^{5-8}$ The prevalence of visual impairment in children with $\mathrm{HI}$ injury may be as high as 66 and $94 \% .^{9}$ Most of the visual dysfunctions attributed to hypoxic-ischemic brain injury are related to retinal damage. Previous studies have suggested that visual loss in perinatal $\mathrm{HI}$ patients is associated with retroretinal and intracerebral visual pathways. ${ }^{5,7,10-14}$ Subsequent experimental studies revealed that ischemic retinal damage (IRD) is another contributing factor for visual impairments in developing neonatal retina. ${ }^{9,15}$

Perinatal $\mathrm{HI}$ can itself cause intraocular hemorrhage (IOH), ${ }^{16}$ which may cause local IRD through several mechanisms in addition to general retinal ischemia. Retinal hemorrhages in perinatal $\mathrm{HI}$ patients, as a retinal examination finding, are pointed out in a small number of publications. ${ }^{16,17}$ In the era of therapeutic hypothermia (TH), there is no data on retinal ophthalmoscopic examination findings in cooled babies diagnosed with NE.

In this study, we aimed to evaluate the early retinal ophthalmoscopic findings in moderate-to-severe NE who underwent $\mathrm{TH}$. We assessed the relationship between early retinal findings and coagulation parameters, blood/blood product transfusion requirement, magnetic resonance imagingmagnetic resonance spectroscopy (MRI-MRS) and amplitudeintegrated electroencephalography (aEEG) findings.

\section{Patients and Methods}

This cross-sectional cohort study was approved by Erciyes University Clinical Research Ethics Committee. Informed written consent was taken from all the parents.

A total of 41 newborn infants who were followed up at neonatal intensive care unit (NICU) of our hospital during February 2015 to August 2016 were included in the study. The inclusion and exclusion criteria were depicted in - Table 1. ${ }^{18}$ Clinical severity of NE was determined using the Sarnat and Sarnat criteria. TH was started as a standard care in all babies that meet the criteria within 6 hours after birth using total body cooling device (Arctic Sun 5000, Medivance, CO, USA) in NICU settings. According to our clinical protocol, targeted core (rectal) temperature is $33.5^{\circ} \mathrm{C}$ for 72 hours. During rewarming period, targeted hourly body temperature rise rate is $0.25^{\circ} \mathrm{C}$. According to the protocol of our clinic, an umbilical vein catheter was inserted to all patients admitted to the NICU and no heparinized fluid was given for its continuity.

Raw EEG and aEEG recordings were started simultaneously with $\mathrm{TH}$ and continued until the end of the rewarming period (Nicolet-NicoletOne, Natus, CA, USA). A pattern classification was used for interpretation of aEEG according to the previously published data by Hellström-Westas L et al. ${ }^{19}$ At the end of the first 24 hours of TH, aEEG patterns
Table 1 Inclusion criteria of the subjects ${ }^{a}$

\begin{tabular}{l} 
Inclusion criteria \\
\hline The babies will be assessed sequentially for criteria A and B \\
listed below
\end{tabular}

A. Condition at birth: Infants $\geq 36$ completed weeks' gestation admitted to the NICU with at least one of the following

Apgar score of $<5$ at 10 minutes after birth due to birth asphyxia/perinatal depression

Continued need for resuscitation, including endotracheal or mask ventilation, at 10 minutes after birth

Acidosis within 60 minutes of birth (defined as any occurrence of umbilical cord, arterial or capillary $\mathrm{pH}<7.00$ )

Base deficit ( $\geq-16 \mathrm{mmol} / \mathrm{L}$ ) in umbilical cord or any blood sample (arterial, venous, or capillary) taken within 60 minutes of birth

Infants that meet criteria A will be assessed by the attending neonatologist for criteria $B$

B. Neurological assessment: Evidence of moderate-to-severe encephalopathy, consisting of altered state of consciousness (lethargy, stupor, or coma) and at least one of the following

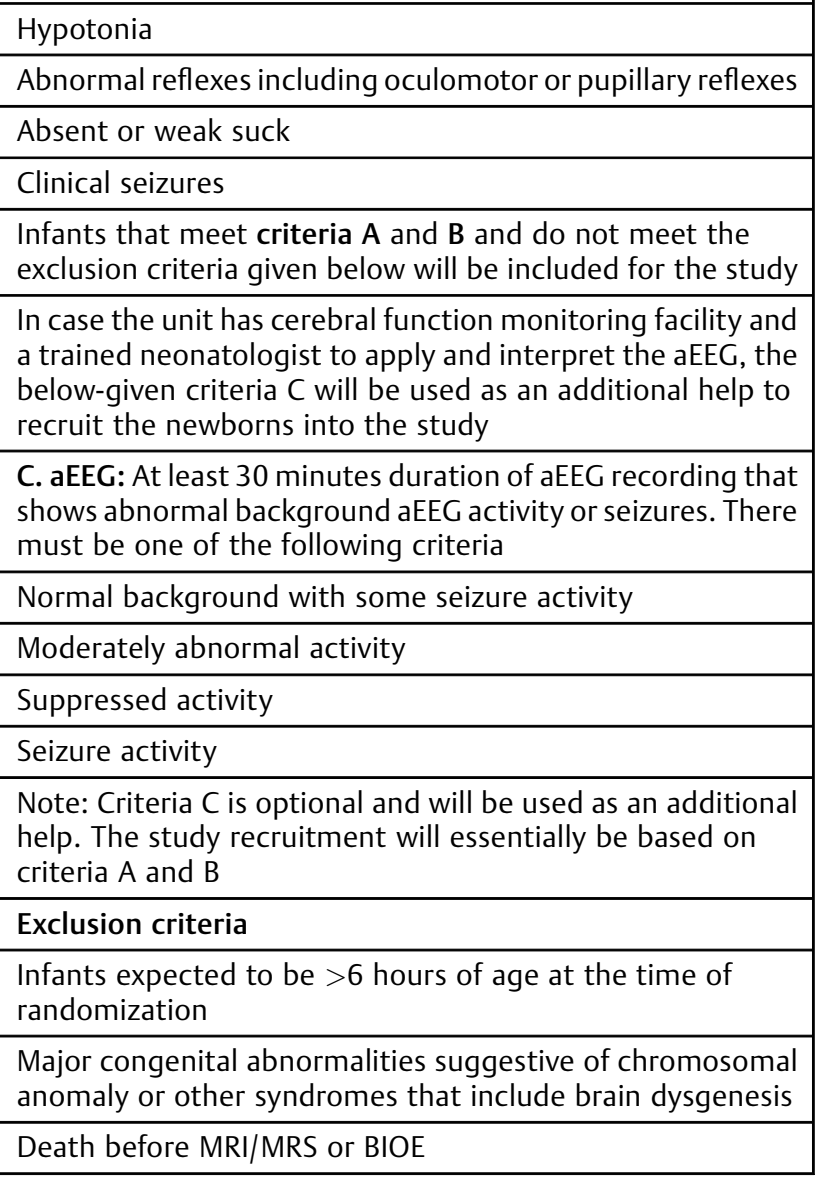

Abbreviations: aEEG, amplitude integrated electroencephalogram; $\mathrm{BIOE}$, binocular indirect ophthalmoscopic examination; NICU, neonatal intensive care unit.

${ }^{\mathrm{a}}$ The panel has been adapted from reference 18 .

were evaluated. Continuous and discontinuous background pattern in aEEG tracing was defined as normal. Other types of tracings (burt-suppression, low voltage, and flat trace) were regarded as abnormal. 


\section{Blood Parameters and Blood Products Transfusion}

Blood samples for complete blood count (CBC) and coagulation tests were obtained from the umbilical vein at the first admission to the NICU before administration of any drug or fluid (other than given during resuscitation) and just before the initiation of $\mathrm{TH}$.

An automated complete blood counter (Sysmex XN 1000, IL, USA) was used for CBC analysis. Coagulation tests including prothrombin time (PT), activated partial thromboplastin time (aPTT), and international normalized ratio (INR) were measured by Sysmex CA 1500 (IL, USA).

During TH clotting tests and $\mathrm{CBC}$ were checked daily. The FFP and PLT transfusion strategy for those patients is defined as INR $\geq 2,{ }^{20}$ and/or when the PT prolongation is more than 1.5 times of normal value, ${ }^{21}$ for PLT suspension PLT counts ${ }^{20}$ $<130 \times 10^{9}$ L. $^{22}$ For red blood cell (RBC) transfusion, the national guideline was used. According to this, if patient requires $>35 \%$ fraction of inspired oxygen $\left(\mathrm{FiO}_{2}\right)$ support or mechanical ventilation critical hemoglobin (Hgb) level for $\mathrm{RBC}$ transfusion is defined as $<12 \mathrm{~g} / \mathrm{dL}$, and if patient requires less than $35 \% \mathrm{FiO}_{2}$ or no $\mathrm{O}_{2}$ support $\mathrm{Hgb}$ level for $\mathrm{RBC}$ transfusion is $<10 \mathrm{~g} / \mathrm{dL}^{21}$

\section{Binocular Indirect Ophthalmoscopic Examination}

Binocular indirect ophthalmoscopic examination (BIOE) was performed by an experienced pediatric ophthalmologist blinded to the neonatal course and MRI-MRS scanning findings by using BIO when $\mathrm{TH}$ and rewarming implementation was terminated, and the patients were clinically stabilized. Mydriatic eye drops to dilate the pupils are routinely administered before retinal examinations. A combination of cyclopentolate $0.2 \%$, an anticholinergic drug, and phenylephrine $1 \%$, an $\alpha$-adrenergic drug, was used to dilate the pupil.

The newborns with IOH lesions were re-examined every 1 or 2 weeks until the lesions were resolved completely.

\section{MRI-MRS Scanning}

MRI and MRS scanning were performed within the first 2 weeks of life, after the TH protocol had been completed and patient stability confirmed. MRI and MRS scanning were performed after sedation. First, passive sedation with breast milk or a pacifier was tried, if needed, oral/rectal chloral hydrate or oral midazolam was given for self-ventilating infants or intravenous midazolam for those who were mechanically ventilated. Neonatal intensive care including inotrope and/or mechanical ventilation support was continued throughout when indicated, and monitoring including pulse oximetry, skin temperature, and apnea alarm was done. A pediatrician and a NICU nurse were always present during MRI-MRS scan.

An 8-channel transmit/receive head coil of a 1.5T Magnetom Sonata system (Siemens AG, Erlangen, Germany) was used for proton $(1 \mathrm{H})$ MRS and MRI. MRI protocol including MRI T2 relaxometry and $1 \mathrm{H}$ MRS was done as previously described by Shanmugalingam et al. ${ }^{23}$ Diffusion-weighted imaging and susceptibility-weighted imaging were gained. We reported specifically the data related to intracranial hemorrhage (ICH) and/or infarcts obtained from MRI scan in this study.

Metabolite peak-area ratios including lactate/ $\mathrm{N}$-acetylaspartate (Lac/NAA), Lac/Cr, Lac/Cho, NAA/Cr, NAA/Cho, and $\mathrm{Cho} / \mathrm{Cr}$ were measured from the 8-mL cubic PRESS voxel and centered on the thalami and the midline by using the sagittal image (TE 270 milliseconds, TR 2 seconds spectrum). Lac/ NAA ratio, which is a useful predictor of adverse outcomes, was used for the evaluation of the severity of the brain damage. $^{23}$ Similar thresholds for Lac/NAA peak-area ratios as those used by Shanmugalingam et al were used to predict neurodevelopmental outcome. ${ }^{23}$ Lac/NAA peak-area ratio of $\leq 0.23,0.24$ to 0.41 , and $>0.42$ were classified as normal, mild-to-moderate, and severe respectively.

\section{Statistical Analysis}

Data entry and analyses were made using IBM SPSS Statistics, version 20. Descriptive statistical methods (mean and standard deviation), chi-square $\left(\mathrm{X}^{2}\right)$, and Fisher's exact test were used for qualitative data determination. Data were expressed as mean \pm standard deviation, unless otherwise specified.

Distributions of the data were tested by Shapiro-Wilk test. Comparisons between the groups were made by the Mann-Whitney U test and Kruskal-Wallis one-way analysis. A $p$-value of less than 0.05 was considered statistically significant.

\section{Results}

During the study period, 41 infants were enrolled in the study, but 10 of them were excluded from the study because they died before BIOE and/or MRI-MRS scanning. The study was completed with the remaining subjects $(n=31)$, who were born at a mean gestational age of 38.8 ( \pm 1.4 ) weeks and had a birth weight of $3190 \pm 467.4 \mathrm{~g}$. One patient was diagnosed with postnatal collapse. The anthropometric and descriptive features of the subjects are shown in - Table 2. Mode of delivery and sex were not related to BIOE findings in our patients.

Initial coagulation status including PLT counts, PT, aPTT, and INR results are shown in - Table 2. A total of 12 (38.7\%) patients had disturbed coagulation status in the initial test results.

During TH and rewarming period, 7 (22.6\%) patients were given PLT transfusion(s), 16 (51.6\%) patients required FFP transfusion(s) due to abnormal test results and some active hemorrhages involving pulmonary and gastrointestinal system. The number of patients who required both PLT and FFP transfusion was 7 (22.6\%) (-Table 2).

BIOE was performed at mean 11.8 ( \pm 7.9 ) days. The number of patients with abnormal BIOE findings was 13 (41.9\%). Ten of them (77\%) had IOH findings in optic disc $(n=2)$, retina $(\mathrm{RH})(n=7)$, or vitreous $(\mathrm{VH})(n=1)$. BIOE findings were summarized in - Table 3. IOHs were detected as more bilaterally than unilaterally $(n=7, n=3$, respectively). All hemorrhages resolved within 4 weeks, except in one patient with unilateral $\mathrm{VH}$ which persisted up to 
Table 2 Demographic features and clinical and laboratory findings of subjects

\begin{tabular}{|c|c|c|}
\hline \multirow[t]{2}{*}{$\operatorname{Sex}(n, \%)$} & Females & $12(38.7)$ \\
\hline & Males & $19(61.3)$ \\
\hline $\begin{array}{l}\text { Birthweight, } \\
\text { (g; mean } \pm \text { SD) }\end{array}$ & $3190 \pm 467$ & \\
\hline \multirow{2}{*}{$\begin{array}{l}\text { Mode of delivery } \\
(n, \%)\end{array}$} & Vaginal & $12(38.7)$ \\
\hline & $\mathrm{C} / \mathrm{S}$ & $19(61.3)$ \\
\hline $\begin{array}{l}\text { Gestational age } \\
(\mathrm{w} ; \text { mean } \pm \mathrm{SD})\end{array}$ & \multicolumn{2}{|l|}{$38.8 \pm 1.4$} \\
\hline \multirow{4}{*}{$\begin{array}{l}\text { Initial clotting test } \\
\text { results } \\
\left(\times 10^{3} / \mathrm{mm}^{3} ;\right. \\
\text { mean } \pm \mathrm{SD}) \\
(\mathrm{s} ; \text { mean } \pm \mathrm{SD})\end{array}$} & PLT counts & $240.4 \pm 92.3$ \\
\hline & PT & $19.1 \pm 6.6$ \\
\hline & INR & $1.7 \pm 0.7$ \\
\hline & PTT & $44.0 \pm 19.9$ \\
\hline \multirow{2}{*}{$\begin{array}{l}\text { PLT transfusion(s) } \\
(n, \%)\end{array}$} & Not required & $24(77.4)$ \\
\hline & Required & $7(22.6)$ \\
\hline \multirow{2}{*}{$\begin{array}{l}\text { FFP transfusion(s) } \\
(n, \%)\end{array}$} & Not required & $15(48.4)$ \\
\hline & Required & $16(51.6)$ \\
\hline \multirow[t]{2}{*}{ aEEG findings ( $>24 \mathrm{~h}$ ) } & Normal trace & $18(58.1)$ \\
\hline & Abnormal trace & $13(41.9)$ \\
\hline $\begin{array}{l}\text { MR scan timing } \\
{[(\mathrm{d} ; \text { median (range) }]}\end{array}$ & \multicolumn{2}{|l|}{$9(5-15)$} \\
\hline \multirow[t]{2}{*}{ MRI findings ( $n, \%)$} & $\begin{array}{l}\text { Intracranial } \\
\text { hemorrhage }\end{array}$ & $6(\% 19.4)$ \\
\hline & Infarct & $4(12.9)$ \\
\hline \multirow[t]{3}{*}{ Lac/NAA ratio } & Normal & $8(25.8)$ \\
\hline & Mild-to-moderate & $9(29)$ \\
\hline & Severe & $14(45.2)$ \\
\hline $\begin{array}{l}\text { BIOE timing } \\
{[(\mathrm{d} ; \text { mean } \pm \mathrm{SD})]}\end{array}$ & $11.8( \pm 7.9)$ & \\
\hline \multirow[t]{2}{*}{ BIOE findings $(n, \%)$} & $\begin{array}{l}\text { No abnormal } \\
\text { finding }\end{array}$ & $18(58.1)$ \\
\hline & $\begin{array}{l}\text { Pathologic } \\
\text { findings }\end{array}$ & $13(41.9)$ \\
\hline
\end{tabular}

Abbreviations: aEEG, amplitude integrated electroencephalogram; $\mathrm{BIOE}$, binocular indirect ophthalmoscopic examination; FFP, fresh frozen plasma; g, gram; INR, international normalized ratio; $\mathrm{IOH}$, intraocular hemorrhage; Lac; Lactate; MRI, magnetic resonance imaging; NAA, Nacetylaspartate; PLT, platelet; SD, standard deviation; w, week. ${ }^{\mathrm{a}}$ The number of patients who received FFP and/or PLT solution.

10 weeks. - Table 4 shows the relationships between BIOE findings and both laboratory and imaging findings.

The number of patients with no abnormal retinal findings was $18(58.1 \%)$ and three patients had abnormal retinal findings other than hemorrhage. Namely, two patients had IRD findings such as stage 1 retinopathy of prematurity (ROP) and dilated retinal vessels, and one patient had finding of structural retinal disorder, which may be secondary to congenital infection or genetic disorder.

Initial coagulation tests and PLT count were not related to hemorrhagic BIOE findings. Additionally, presence of
Table 3 BIOE findings of patients

\begin{tabular}{|c|c|c|c|c|c|}
\hline \multirow{4}{*}{$\begin{array}{l}\text { BIOE } \\
\text { Findings } \\
(n, \%)\end{array}$} & & Total & Right & Left & Bilateral \\
\hline & $\begin{array}{l}\text { Retinal } \\
\text { hemorrhage }\end{array}$ & $\begin{array}{l}7 \\
(70)\end{array}$ & $\begin{array}{l}1 \\
(14.3)\end{array}$ & $\begin{array}{l}1 \\
(14.3)\end{array}$ & $\begin{array}{l}5 \\
(71.4)\end{array}$ \\
\hline & $\begin{array}{l}\text { Optic disc } \\
\text { hemorrhage }\end{array}$ & $\begin{array}{l}2 \\
(10)\end{array}$ & - & $1(50)$ & $1(50)$ \\
\hline & $\begin{array}{l}\text { Vitreous } \\
\text { hemorrhage }\end{array}$ & $\begin{array}{l}1 \\
(10)\end{array}$ & - & $\begin{array}{l}1 \\
(100)\end{array}$ & - \\
\hline
\end{tabular}

Abbreviation: BIOE, binocular indirect ophthalmoscopic examination.

requirement of PLT and/or FFP transfusion(s) was not related to BIOE findings ( $p>0.05$ ), ( - Table 4 ). Neither initial coagulation test results nor PLT and/or FFP transfusion requirement during management period were related to $\mathrm{ICH}$ findings on MRI ( $p>.05)$, ( - Table 4).

aEEG records revealed abnormal trace after 24 hours of cooling in $13(41.9 \%)$ patients. There was no relationship between aEEG records and BIOE findings $(p>0.05)$ (-Table 4).

MRI-MRS scanning were performed at $8.1( \pm 2.2)$ days. In six (\%19.4) patients, subdural and/or dural and/or parenchymal hemorrhage was detected, and in four (12.9\%) patients brain infarct was detected in MRI scanning. The types of ICHs are shown in - Table 2.

Lac/NAA peak-area ratios on MRS were within normal range in eight $(25.8 \%)$ patients. Metabolite peak-area ratios were consistent with mild-to-moderate outcome in 9 (29\%) patients and with severe outcome in 14 (45.2\%) patients. There was no statistically significant relationship between MRS (Lac/NAA peak-area ratio) and BIOE findings ( $p>0.05)$ (-Table 4).

MRS features of patients with subdural hemorrhage were as follows; one patient (16.7\%) had normal MRS findings, two patients (33.3\%) had mild-to-moderate MRS findings, and three patients (50\%) had severe MRS findings. Three of the patients (75\%) with severe MRS findings had brain infarct. MRI findings including ICH and infarcts were not related to BIOE findings $(p>0.05)$, ( - Table 4$)$.

\section{Discussion}

Earlier studies claimed that visual defects in the braindamaged infants were attributed to the so-called cortical visual impairment caused by pathologies in intracerebral visual pathways which is a large proportion of the human brain's neural substance (i.e., the optic nerves, optic radiations, primary visual cortex, visual associative cortical areas, and/or visual attention pathways ). ${ }^{5,7,10-14}$ Damage to several these different structures can result in significant visual disability. ${ }^{11}$ Clinical manifestations of visual disability are associated with nonvisual neurologic complications, as well as prognosis greatly depending on the site(s) of brain injury. ${ }^{5}$ Perhaps, for this reason, earlier guidelines proposed the ophthalmologic evaluation for neonates underwent moderate-to-severe NE because of the possibility of damage in 
Table 4 Relationships between BIOE findings and both clinical and laboratory findings

\begin{tabular}{|c|c|c|c|c|c|c|}
\hline & & $\begin{array}{l}\text { Normal } \\
(n, \%)\end{array}$ & $\begin{array}{l}\mathrm{IOH} \\
(n, \%)\end{array}$ & $\begin{array}{l}\text { ERIF } \\
(n, \%)\end{array}$ & $\begin{array}{l}\text { Other } \\
(n, \%)\end{array}$ & Total \\
\hline \multirow[t]{2}{*}{ Sex } & $\mathrm{F}$ & $8(66.7)$ & $4(33.3)$ & - & - & 12 \\
\hline & M & $10(52.6)$ & $6(31.6)$ & $2(10.5)$ & $1(5.3)$ & 19 \\
\hline \multirow[t]{2}{*}{ Mode of delivery } & VD & $8(66.7)$ & $3(25.0)$ & $1(8.3)$ & - & 12 \\
\hline & $\mathrm{C} / \mathrm{S}$ & $10(52.6)$ & $7(36.8)$ & $1(5.3)$ & $1(5.3)$ & 19 \\
\hline \multirow{2}{*}{$\begin{array}{l}\text { Low PLT count at } \\
\text { admission }\end{array}$} & $\mathrm{NA}$ & $18(60.0)$ & $9(30.0)$ & $2(6.7)$ & $1(3.3)$ & 30 \\
\hline & A & - & $1(100)$ & - & - & 1 \\
\hline \multirow{2}{*}{$\begin{array}{l}\text { Disturbed coagulation } \\
\text { status at the admission }\end{array}$} & NA & $11(61.1)$ & 7 (38.9) & - & - & 18 \\
\hline & $A$ & $7(53.8)$ & $3(23.1)$ & $2(15.4)$ & $1(7.7)$ & 13 \\
\hline \multirow{2}{*}{$\begin{array}{l}\text { PLT transfusion(s) } \\
\text { requirement status }\end{array}$} & NA & $15(62.5)$ & $8(33.3)$ & $1(4.2)$ & - & 24 \\
\hline & $A$ & $3(42.9)$ & $2(28.6)$ & $1(14.3)$ & $1(14.3)$ & 7 \\
\hline \multirow{2}{*}{$\begin{array}{l}\text { FFP transfusion(s) } \\
\text { requirement status }\end{array}$} & $\mathrm{NA}$ & $10(66.7)$ & $4(26,7)$ & $1(6,7)$ & - & 15 \\
\hline & $A$ & $8(50)$ & $6(37.5)$ & $1(6.2)$ & $1(6.2)$ & 16 \\
\hline \multirow[t]{2}{*}{ aEEG pattern } & Normal & $10(55.6)$ & $7(38.9)$ & - & $1(5.6)$ & 18 \\
\hline & Abnormal & $8(61.5)$ & $3(23.1)$ & $2(15.4)$ & - & 13 \\
\hline \multirow[t]{2}{*}{ MRI findings } & Hemorrhage & $4(66.7)$ & $1(16.7)$ & $1(16.7)$ & - & 6 \\
\hline & Infarct & $3(75.0)$ & $1(25.0)$ & - & - & 4 \\
\hline \multirow[t]{3}{*}{ Lac/NAA ratio } & Normal & $6(75.0)$ & $2(25.0)$ & - & - & 8 \\
\hline & $\begin{array}{l}\text { Mild-to- } \\
\text { moderate }\end{array}$ & $5(55.6)$ & $3(33.3)$ & $1(11.1)$ & - & 9 \\
\hline & Severe & $7(50.0)$ & $5(35.7)$ & $1(7.1)$ & $1(7.1)$ & 14 \\
\hline
\end{tabular}

Abbreviations: A; available; BIOE, binocular indirect ophthalmoscopic examination; $C / S$, caesarian section; ERIF, early retinal ischemic findings; $F$, female; FFP, fresh frozen plasma; IOH, intraocular hemorrhage; Lac, Lactate; M, male; MRI, magnetic resonance imaging; NA, not available; NAA, Nacetylaspartate; NS, not significant; PLT, platelet; VD, vaginal delivery.

posterior visual pathways and secondary amblyopia but not for possible retinal damage. ${ }^{25}$ Recent experimental rodent studies revealed that severity of IRD which occurs during $\mathrm{HI}$ is unrelated to the severity of HI injury, and IRD may be another contributing factor for visual impairments. ${ }^{9,15}$

$\mathrm{IOHs}$ and their effects on developing retina in neonates who underwent TH are usually overlooked by clinicians. A current guideline does not recommend routine retinal examination to evaluate $\mathrm{IOH}$ before discharge for babies with $\mathrm{NE} .^{26}$ IOH caused by perinatal $\mathrm{HI}{ }^{16,17}$ can itself result in IRD. Either small IOHs itself due to locally disturbed circulation in hemorrhagic area or increased intraocular pressure created by excessive IOH causing disturbed retinal circulation, such as $\mathrm{VH}$ or extensive $\mathrm{RH}$, can contribute to an increase in severity of IRD. Excessive IOHs might cause secondary amblyopia of the involved eye in the future life of newborns. Furthermore, increased intraocular pressure created by excessive IOH can contribute to an increase in IRD through a similar pathophysiology in acute glaucoma. ${ }^{24}$ The present study showed that the frequency of IOH is high in newborns with $\mathrm{NE}$ who underwent $\mathrm{TH}$, being independent from severity of aEEG pattern, ICH, MRS findings, and disturbed coagulation status in this population.

Among the potential causes of IOHs are perinatal HI, traumatic delivery, ICH, shaken baby syndrome, and neonatal coagulopathies. ${ }^{16,17}$ The incidence of neonatal $\mathrm{IOH}$ varies according to the timing of the examination being higher in those early-examined neonates. ${ }^{16}$ In our study, we detected $\mathrm{IOH}$ in $32.2 \%(n=10)$ of our patients whose BIOE examinations were performed at $11.8( \pm 7.9)$ days. This is more than a previous clinical study, where the $\mathrm{IOH}$ incidence was $5.5 \%$ at mean 11.5 days, ${ }^{16}$ but the patient group of that study consisted of milder cases of NE compared with our study group. IOHs may be associated with ICH; during HI, disturbed cerebral vascular autoregulation results in raised intracranial pressure which in turn increases the retinal venous pressure. The risk of $\mathrm{IOH}$ is increased by retinal venous stasis, disturbed vascular fragility and fluctuating systemic arterial pressure during resuscitation in newborns. ${ }^{27,28}$ In our cases, there was no history of traumatic birth and mode of delivery was not related to IOH. ICH was detected on MRI in six (19.4\%) patients and we did not find any relationship with IOH frequency and ICH. The absence of any relationship with frequency of ICH and IOH might be related to small numbers. In our study, all patients were clinically diagnosed with moderate-to-severe $\mathrm{NE}$ and underwent $\mathrm{TH}$. We argue that moderate-to-severe NE despite the fact that the unknown frequency of ICH and IOH in dead patients might be an explanation for the high frequency of $\mathrm{IOH}$ detected in our patients. As all patients underwent TH, we cannot determine the possible effect of $\mathrm{TH}$ on $\mathrm{IOH}$. 
Coagulation defects are challenging particularly in neonates diagnosed with NE and undergoing TH. Perinatal HI can cause coagulation disturbances due to mechanical ${ }^{27}$ and maternal factors and impaired synthesis of clotting factors and PLT, as well as disseminated intravascular coagulation. ${ }^{20}$ Additionally, hypothermia results in a slowing enzymatic function of the coagulation cascade, thrombin generation, and PLT dysfunction. ${ }^{20,29,30}$ In our cases, almost one out of four patients had required PLT transfusion(s) (22.6\%), while FFP transfusion(s) were given in more than half of $(51.6 \%)$ them. We haven't detected any statistical relationship between frequency of disturbed initial coagulation tests and frequency of $\mathrm{IOH}$ in our patients. Additionally, PLT and/or FFP transfusion requirement during management of $\mathrm{TH}$ was not related to frequency of $\mathrm{IOH}$. Therefore, we speculate that $\mathrm{IOH}$ might be an independent component of clinical constellation in neonates diagnosed with moderateto-severe NE who underwent $\mathrm{TH}$, like other problems (i.e., renal insufficiency, hepatic dysfunction, and convulsions). This might be an outcome of multiple disturbances including $\mathrm{ICH}$, disturbed retinal vascular integrity and stasis/congestion, and impaired coagulation status by perinatal $\mathrm{HI}$ and/or $\mathrm{TH}$.

Experimental asphyctic animal studies showed that IRD results in ganglion cell degeneration and neovascularization of the most inner layers of the retina. ${ }^{3,31-33}$ IRD causes retinal remodeling called as ischemic proliferative retinopathy. ${ }^{22,31,32}$ Regarding the functional changes, HI induces a functional impairment of the inner retina and rod and conemediated inner retinal functions, while sparing the photoreceptor functions and activity. ${ }^{15}$ One of our patient had stage 1 ROP and severe MRS findings and required multiple PLT and FFP transfusions as well. Considering having the same mechanistic, the finding of ROP in this patient may point out IRD. ${ }^{22}$ In another patient, dilated retinal vessels were detected which might be considered as IRD and/or retinal vascular stasis such as seen in diabetic retinopathy. 22,24

The retina has the highest oxygen expenditure per volume in the body. ${ }^{22}$ The developing retina is highly sensitive to variation in oxygen levels and highly susceptible to oxidative damage by reactive oxygen species (ROS), as well as overproduced nitric oxide (NO) creating reactive nitrogen species (RNS). ${ }^{9,15,22}$ NO is the most widespread intercellular messenger in the retina and nitric oxide synthesis (NOS) systems which are located predominantly at the inner margin of retina. $^{34,35}$ Interestingly, NOS activity pattern in CNS is different from retina. Animal studies revealed that NOS isoforms activity in CNS is increased by hypoxia at early postnatal period and significantly declines thereafter. $^{31,34,36-38}$ In contrast, in the retina, induced longterm alterations in the activity of NOS systems by HI started at late postnatal stages and remained high for long time and early applied hypothermia had beneficial effects on these diverse retinal NOS systems. ${ }^{34}$ We think that this unique activity of different NOS isoforms occurring at different times may be the reason for the lack of similarity of retinal and CNS damage severity after HI. In several studies, TH was shown to prevent IRD by inhibiting expressions of some factors that target for hypoxia-inducible factor- $1 \beta$ including nNOS, iNOS, vascular endothelial growth factor, and adrenomedullin (AM), and nitration of proteins. ${ }^{22,31,32,34}$ Although these beneficial effects of $\mathrm{TH}$ on IRD in animal studies are encouraging, there is no study in human newborns. The effect of $\mathrm{TH}$ on the increased risk of $\mathrm{IOH}$ in neonates with NE who underwent $\mathrm{TH}$ remains unclear. We believe that beneficial effects of TH on IRD might be limited due to increasing possibility of $\mathrm{IOH}$ resulted from multiple disturbances, as described above.

We are aware of the limitations of the current study. The lack of retinal examination at the admission/before $\mathrm{TH}$ in patients with moderate-to-severe NE does not allow us to comment on the real frequency of $\mathrm{IOH}$. Also, we were not able to do daily BIOE to prevent increased light exposure and stimulant for maximum neuronal protection. Wide variation in BIOE timing due to the fact that we have to wait for patients to be clinically stable is another limitation of study. In addition, the small number of patients and lack of control group caused inadequacy in determining the reason of the high rate of $\mathrm{IOH}$ in our patients. The data obtained from our work will be useful for future studies. We believe that further clinical studies are needed to evaluate retinal changes in newborns with NE. In addition, well-designed experimental studies would shed light on understanding the mechanisms of these disturbances and possible adverse or beneficial effects of $\mathrm{TH}$ on retinal changes in this specific group of newborns.

In conclusion, while TH reduces IRD caused by RNS and ROS, its effect on the increased frequency IOH is not clear. In this study, we found that the frequency of $\mathrm{IOH}$ is high and independent from ICH, coagulation status, and neurodevelopmental prognostic parameters including MRS findings as well as aEEG findings in neonates diagnosed with NE who underwent $\mathrm{TH}$.

Declaration of Interest

The authors report no conflicts of interest.

\section{References}

1 Nelson KB, Leviton A. How much of neonatal encephalopathy is due to birth asphyxia? Am J Dis Child 1991;145(11):1325-1331

2 Younkin DP. Hypoxic-ischemic brain injury of the newbornstatement of the problem and overview. Brain Pathol 1992;2 (03):209-210

3 Osborne NN, Casson RJ, Wood JP, Chidlow G, Graham M, Melena J. Retinal ischemia: mechanisms of damage and potential therapeutic strategies. Prog Retin Eye Res 2004;23(01):91-147

4 Sickel W. Electrical and metabolic manifestations of receptor and higher-order neuron activity in vertebrate retina. Adv Exp Med Biol 1972;24(00):101-118

5 Hoyt CS. Brain injury and the eye. Eye (Lond) 2007;21(10): 1285-1289

6 Chong CF, McGhee CN, Dai S. A cross-sectional study of prevalence and etiology of childhood visual impairment in Auckland, New Zealand. Asia Pac J Ophthalmol (Phila) 2014;3(06):337-342

7 Huo R, Burden SK, Hoyt CS, Good WV. Chronic cortical visual impairment in children: aetiology, prognosis, and associated neurological deficits. Br J Ophthalmol 1999;83(06):670-675

8 Chong C, Dai S. Cross-sectional study on childhood cerebral visual impairment in New Zealand. J AAPOS 2014;18(01):71-74 
9 Huang HM, Huang CC, Hung PL, Chang YC. Hypoxic-ischemic retinal injury in rat pups. Pediatr Res 2012;72(03):224-231

10 Eken P, de Vries LS, van der Graaf Y, Meiners LC, van Nieuwenhuizen $\mathrm{O}$. Haemorrhagic-ischaemic lesions of the neonatal brain: correlation between cerebral visual impairment, neurodevelopmental outcome and MRI in infancy. Dev Med Child Neurol 1995; 37(01):41-55

11 Hoyt CS. Visual function in the brain-damaged child. Eye (Lond) 2003;17(03):369-384

12 Brodsky MC, Fray KJ, Glasier CM. Perinatal cortical and subcortical visual loss: mechanisms of injury and associated ophthalmologic signs. Ophthalmology 2002;109(01):85-94

13 Salati R, Borgatti R, Giammari G, Jacobson L. Oculomotor dysfunction in cerebral visual impairment following perinatal hypoxia. Dev Med Child Neurol 2002;44(08):542-550

14 Van Hof-van Duin J, Mohn G. Visual defects in children after cerebral hypoxia. Behav Brain Res 1984;14(02):147-155

15 Jung S, Polosa A, Lachapelle P, Wintermark P. Visual Impairments following term neonatal encephalopathy: do retinal impairments also play a role? Invest Ophthalmol Vis Sci 2015;56(09):5182-5193

16 Choi YJ, Jung MS, Kim SY. Retinal hemorrhage associated with perinatal distress in newborns. Korean J Ophthalmol 2011;25 (05):311-316

17 Shaikh S, Fishman ML, Gaynon M, Alcorn D. Diffuse unilateral hemorrhagic retinopathy associated with accidental perinatal strangulation. A clinicopathologic report. Retina 2001;21(03): 252-255

18 Rahman SU, Canpolat FE, Oncel MY, et al. Multicenter randomized controlled trial of therapeutic hypothermia plus magnesium sulfate versus therapeutic hypothermia plus placebo in the management of term and near-term infants with hypoxic ischemic encephalopathy (The Mag Cool study): a pilot study. J Clin Neonatol 2015;4:158-163

19 Hellström-Westas L, Rosén I, Svenningsen NW. Predictive value of early continuous amplitude integrated EEG recordings on outcome after severe birth asphyxia in full term infants. Arch Dis Child Fetal Neonatal Ed 1995;72(01):F34-F38

20 Forman KR, Diab Y, Wong EC, Baumgart S, Luban NL, Massaro AN. Coagulopathy in newborns with hypoxic ischemic encephalopathy (HIE) treated with therapeutic hypothermia: a retrospective case-control study. BMC Pediatr 2014;14:277

21 Perk Y, Atasay B, Cetinkaya M. Türk Neonatoloji Derneği Kan Ürünleri Transfüzyon Rehberi-2016. Internet, http://neonatology.org.tr/wp-ontent/uploads/2016/12/kan_urunleri_transfuzyonu.pdf

22 Li SY, Fu ZJ, Lo AC. Hypoxia-induced oxidative stress in ischemic retinopathy. Oxid Med Cell Longev 2012;2012:426769

23 Shanmugalingam S, Thornton JS, Iwata O, et al. Comparative prognostic utilities of early quantitative magnetic resonance imaging spin-spin relaxometry and proton magnetic resonance spectroscopy in neonatal encephalopathy. Pediatrics 2006;118 (04):1467-1477

24 Flammer J, Konieczka K, Bruno RM, Virdis A, Flammer AJ, Taddei S. The eye and the heart. Eur Heart J 2013;34(17):1270-1278

25 Robertson CM, Perlman M. Follow-up of the term infant after hypoxic-ischemic encephalopathy. Paediatr Child Health 2006;11 (05):278-282

26 Azzopardi D. Clinical management of the baby with hypoxic ischaemic encephalopathy. Early Hum Dev 2010;86(06):345-350

27 Ladjimi A, Zaouali S, Messaoud R, et al. Valsalva retinopathy induced by labour. Eur J Ophthalmol 2002;12(04):336-338

28 Smith DC, Kearns TP, Sayre GP. Preretinal and optic nerve-sheath hemorrhage: pathologic and experimental aspects in subarachnoid hemorrhage. Trans Am Acad Ophthalmol Otolaryngol 1957; 61(02):201-211

29 Michelson AD, Barnard MR, Khuri SF, Rohrer MJ, MacGregor H, Valeri CR. The effects of aspirin and hypothermia on platelet function in vivo. Br J Haematol 1999;104(01):64-68

30 Wolberg AS, Meng ZH, Monroe DM III, Hoffman M. A systematic evaluation of the effect of temperature on coagulation enzyme activity and platelet function. J Trauma 2004;56(06):1221-1228

31 Rey-Funes M, Dorfman VB, Ibarra ME, et al. Hypothermia prevents gliosis and angiogenesis development in an experimental model of ischemic proliferative retinopathy. Invest Ophthalmol Vis Sci 2013;54(04):2836-2846

32 Rey-Funes M, Ibarra ME, Dorfman VB, et al. Hypothermia prevents the development of ischemic proliferative retinopathy induced by severe perinatal asphyxia. Exp Eye Res 2010;90(01):113-120

33 Hofman P, van Blijswijk BC, Gaillard PJ, Vrensen GF, Schlingemann RO. Endothelial cell hypertrophy induced by vascular endothelial growth factor in the retina: new insights into the pathogenesis of capillary nonperfusion. Arch Ophthalmol 2001;119(06):861-866

34 Rey-Funes M, Ibarra ME, Dorfman VB, et al. Hypothermia prevents nitric oxide system changes in retina induced by severe perinatal asphyxia. J Neurosci Res 2011;89(05):729-743

35 Eldred WD, Blute TA. Imaging of nitric oxide in the retina. Vision Res 2005;45(28):3469-3486

36 Dorfman VB, Rey-Funes M, Bayona JC, López EM, Coirini H, Loidl CF. Nitric oxide system alteration at spinal cord as a result of perinatal asphyxia is involved in behavioral disabilities: hypothermia as preventive treatment. J Neurosci Res 2009;87 (05):1260-1269

37 Fernández AP, Alonso D, Lisazoaín I, et al. Postnatal changes in the nitric oxide system of the rat cerebral cortex after hypoxia during delivery. Brain Res Dev Brain Res 2003;142(02):177-192

38 Ekimova IV. Changes in the metabolic activity of neurons in the anterior hypothalamic nuclei in rats during hyperthermia, fever, and hypothermia. Neurosci Behav Physiol 2003;33(05):455-460 